\title{
KEUNIKAN DAN OTENTISITAS PASAR EKSTRIM WILKEN \\ SEBAGAI DAYA TARIK WISATA DI KOTA TOMOHON SULAWESI UTARA
}

\author{
Ingryt Grity Adipati \\ Prodi Magister Pariwisata, Universitas Udayana \\ Email: grityadipati.ga@gmail.com \\ I Gde Pitana \\ Universitas Udayana \\ Email: pitana@unud.ac.id \\ Gde Indra Bhaskara \\ Universitas Udayana \\ Email: gbhaskara@unud.ac.id
}

\begin{abstract}
Wilken Extreme Market is a unique and authentic traditional market in Tomohon City which sells all kinds of meats that are not normally consumed such as snake meat, forest rats, bats, cats, and dogs. This has become the center of attention for tourists to visit because the existence of this destination makes gastronomic tourism for the Minahasan people known as being the only extreme market in Indonesia that is the identity of tourism in North Sulawesi. This study uses a qualitative descriptive approach, data sources obtained through observation, interviews and documentation. The data analysis used in this study is the phenomenological method to understand what experiences are obtained and could see the final results in maintaining and developing uniqueness and authenticity, especially in trading extreme meat as a tourist attraction. The results of the study after obtaining the required data indicate the uniqueness and authenticity of the extreme market of Wilken Tomohon, that some of the meat for sale is hunted by the Minahasa community, and other types of meat are sent from different regions. called extreme markets and extreme foods. This market also has superior value for cultural, environmental and economic benefits that affect the uniqueness and authenticity of extreme markets, so that as a market traders it has its own meaning to be able to continue trading activities and focus more on market conditions, which are tourist attractions, as well as the government tourism department. , market managers, as well as travel agencies interpreting the uniqueness and authenticity of the market as local wisdom that contains elements of cultural tourism and gastronomic tourism in Extreme Markets as tourist attractions while maintaining the authenticity of the market so that it remains unique and authentic.
\end{abstract}


The uniqueness and the authenticity of Wilken extreme market as a tourist attraction in Tomohon City, is expected to survive in a sustainable manner as a tourist attraction for the government and local communities.

Keywords: Authenticity, cultural tourism, extreme market, gastronomic tourism, uniqueness.

\section{Pendahuluan}

Kuliner atau masakan lokal merupakan daya tarik wisata yang kuat dan penting bagi wisatawan dalam melakukan perjalanan untuk memenuhi suatu tujuan. Hal ini juga merupakan aktivitas non-musiman yang dapat membantu memajukan pendapatan ekonomi daerah. Selain kuliner ciri khas budaya lokal yang merupakan destinasi wisata, ada juga yang disebut dengan culinary adventure, extreme food, food cultural, dan weird food dimana ada tawaran khusus untuk minat wisatawan mengambil keputusan bisa menikmati apa yang ditawarkan untuk dikonsumsi seperti yang biasa dilakukan oleh masyarakat lokal yang memiliki daya tarik daerah tujuan wisata itu sendiri.

Diantara banyaknya destinasi alam yang terdapat di Kota Tomohon, Pasar Ekstrim Wilken Tomohon terkenal dengan kata Ekstrim atau pasar yang tidak biasa itu sebagai pasar masyarakat lokal yang menjual daging hewan seperti babi hutan, monyet, ular sanca python, tikus hutan, kelelawar, biawak, kodok, kucing, dan anjing. Budaya ini sudah ada sejak lama sebelum masuknya jaman modern, dan jika tidak dilestarikan maka keberadaan pasar ini tidak akan memiliki nilai kebudayaan yang berkelanjutan.

Memakan daging anjing atau kucing bisa memberikan rasa hangat bagi tubuh setelah dikonsumsi, apalagi daging kucing yang bisa menyembuhkan sakit asma atau sesak napas, begitu juga dengan daging ular yang bisa mempercantik kulit menjadi lebih mulus dan tidak kasar. daging kucing, anjing, dan ular ini juga bisa dimakan dengan nasi putih agar lebih nikmat rasanya apalagi langsung disajikan setelah selesai 
dimasak, begitupun dengan daging ekstrim lainnya semua lebih cocok dimakan dengan nasi putih hangat. Hal ini yang menjadi pusat perhatian wisatawan untuk dikunjungi karena adanya destinasi tersebut membuat wisata kuliner orang Minahasa dikenal dan menjadi satu-satunya pasar ekstrim yang menjadi Icon atau lambang dari wisata kuliner di Sulawesi Utara. Dikenal jauh semenjak tahun 1950-an, masyarakat yang ada di Minahasa bertahan hidup di hutan dengan memakan daging monyet dan ular selama era konflik bersenjata dan kebiasaan ini menjadi suatu makanan khas bagi orang Minahasa hingga sekarang.

Sebuah perjalanan dan pengalaman yang ekstrim biasa disebut dengan dark tourism sering dilakukan oleh beberapa wisatawan. Tempat-tempat yang berhubungan dengan kematian, penjara, bahkan pembunuhan bukanlah fenomena hal baru dimana wisatawan dengan sengaja atau tidak sengaja telah lama tertarik pada sisi gelap pariwisata. Rasa ingin tahu dari setiap wisatawan akan situs budaya dan pertunjukan yang terkait dengan salah satu cara kematian, penderitaan, kekerasan, atau bencana (Stone 2005a; Seaton, Forthcoming).

Konsep wisata kuliner menurut Harvey (2012) mendefinisikan wisata kuliner sebagai kegiatan pariwisata untuk mempelajari bagaimana memberi apresiasi terhadap makanan dan minuman pada suatu destinasi wisata karena itu merupakan bentuk kearifan lokal, budaya, tradisi dari destinasi wisata yang dikunjungi oleh wisatawan.

Menurut Hu dan Ritchie (1993), destinasi adalah sebuah paket (bundle) yang terdiri dari berbagai fasilitas dan layanan pariwisata yang seperti produk jasa yang lainnya, terdiri dari sejumlah atribut multidimensi yang bersama-sama menentukan daya tariknya bagi individu tertentu dalam situasi pilihan tertentu.

Pasar Ekstrim mempunyai nama lengkap yaitu Pasar Ekstrim Wilken Kota Tomohon, Sekilas tampilan pasar Ekstrim Wilken seperti pasar tradisional pada umumnya. Di bagian utara pasar adalah pasar tradisional biasa. Berbagai jenis sayur, 
daging ayam, daging sapi, ikan, jajanan, dijual di pasar Ekstrim Tomohon. Biasanya pasar tersebut ramai dengan pengunjung pada hari pasar utama seperti Selasa, Kamis dan Sabtu. Namun jika pengunjung terus menjelajah ke bagian selatan, pasar ini menjual daging dari beragam hewan liar yang tak lazim dikonsumsi. Daging tikus, anjing, kodok, biawak, kelelawar, babi hutan, kucing, bahkan ular piton terpajang di lapak pedagang. Hal ini yang membedakan Pasar Tomohon dengan pasar tradisional lain di Indonesia.

\section{Teori dan Metode}

Penelitian ini menggunakan teori pengembangan pariwisata, teori pemangku kepentingan dan teori supply and demand yang diuraikan sebagai berikut:

\section{Teori Pengembangan Pariwisata}

Menurut Barreto dan Giantari (2015:34) Pengembangan pariwisata adalah suatu usaha untuk mengembangkan atau memajukan objek wisata agar, objek wisata tersebut lebih baik dan lebih menarik ditinjau dari segi tempat maupun benda-benda yang ada didalamnya untuk dapat menarik minat wisatawan untuk mengunjunginya.

\section{Teori Pemangku Kepentingan (Stakeholder)}

Pemangku kepentingan (stakeholders) menurut Reed et al. (2009) yaitu pihak yang dapat memengaruhi atau dipengaruhi oleh capaian dari sasaran organisasi. Pemangku kepentingan merupakan orang dengan suatu kepentingan atau perhatian pada permasalahan (Fletcher et al., 2003) yang diidentifikasi dengan pertimbangan posisi penting dan pengaruh yang dimiliki.

\section{Penawaran dan Permintaan (Supply and Demand)}

Teori penawaran dan permintaan dalam ilmu ekonomi, adalah penggambarkan atas hubungan-hubungan di pasar, antara para calon pembeli dan penjual dari suatu barang. Model penawaran dan permintaan digunakan untuk 
menentukan harga dan kuantitas yang terjual di pasar. Model ini sangat penting untuk melakukan analisis ekonomi mikro terhadap perilaku serta interaksi para pembeli dan penjual.

Penelitian ini merupakan jenis penelitian deskriptif kualitatif yaitu penelitian yang berusaha mendeskripsikan atau menggambarkan/melukiskan fenomena atau hubungan antar fenomena yang diteliti secara sistematis, faktual, dan akurat. Penelitian ini tidak selalu membutuhkan hipotesis, demikian pula dengan perlakuan atau manipulasi terhadap variable-variabel penelitian.

Analisis data yang digunakan dalam penelitian ini yaitu dengan model (Smith:2009) metode fenomenologi adalah mengenai orang yang selalu tidak dapat dihapuskan dari dalam konteks dunianya (person-incontext) dan intersubyektifitas. Teknik pengumpulan data dilakukan melalui observasi, wawancara mendalam, dokumentasi, dan studi kepustakaan. Penentuan informan menggunakan teknik purposive sampling, informan tersebut yaitu Pimpinan Dinas Pariwisata Kota Tomohon, Pedagang Pasar Daerah Kota Tomohon, pengelolah pasar, Travel agent atau Biro Perjalanan dan masyarakat. Analisis data dilakukan secara deskriptif kualitatif dengan memaparkan dan menguraikan data-data yang dikumpulkan selama melakukan penelitian.

\section{Hasil dan Pembahasan}

Pasar Ekstrim ini telah ada sejak ratusan tahun yang lalu, pasar yang sebelumnya bernama Pasar Beriman Tomohon sekarang telah berubah nama pada bulan januari 2020 telah resmi menjadi Pasar Ekstrim Wilken Tomohon, pasar penjual segala macam daging yang menjadi pusat perhatian wisatawan untuk dikunjungi karena adanya destinasi tersebut membuat wisata kuliner orang Minahasa dikenal dan menjadi satu- satunya pasar ekstrim yang menjadi Icon atau lambang dari wisata kuliner yang ada di Sulawesi Utara. 


\section{Subjek Wawancara}

Penelitian dengan metode fenomenologi mendapatkan 14 orang informan untuk diwawancarai, yang memiliki informasi berbeda-beda namun memiliki makna atau maksud tujuan yang sama untuk penelitian ini.

Tabel 1. Subjek Wawancara

\begin{tabular}{lll}
\hline No & Subjek & Keterangan \\
\hline 1 & Pedagang Pasar & 5 Orang \\
2 & Pembeli/Pengunjung Pasar & 2 Orang \\
3 & Pemerintah DISPAR Tomohon & 2 Orang \\
4 & Pengelolah Pasar & 3 Orang \\
5 & Biro Perjalanan (guide) & 2 Orang \\
\hline & Jumlah & 14 Orang \\
\hline
\end{tabular}

Sumber: Data Primer diolah, 2021

Pedagang pasar berjumlah 5 orang yang terdiri dari 2 orang pedagang menjual satu jenis daging dan 3 orang pedagang menjual lebih dari satu jenis daging, dan pembeli berjumlah 2 orang yang datang ke pasar ekstrim dengan tujuan yang berbeda-beda, dari Dinas Pariwisata Kota Tomohon berjumlah 2 orang yang dari bagian pemasaran dan asisten pribadi kepala dinas pariwisata, 3 orang pengelolah pasar, dan 2 orang pemandu wisata (guide) yang merupakan bagian dari pengusaha pariwisata dalam bidang swasta. Informasi dari setiap subjek akan diolah secara rinci dan mudah dimengerti oleh pembaca sehingga dapat memberikan arti dari tujuan penelitian ini. 


\section{Banyaknya Pedagang Daging Ekstrim}

Jumlah pedagang daging ekstrim di Pasar Ekstrim Wilken Tomohon berjumlah 23 orang pedagang, yang semua berasal dari Minahasa meskipun beberapa orang tinggal cukup jauh dari Kota Tomohon.

Tabel 2. Jumlah Pedagang Daging Ekstrim

\begin{tabular}{lll}
\hline No & Jenis Kelamin & Jumlah \\
\hline 1 & Laki-laki & 16 Orang \\
2 & Perempuan & 7 Orang \\
\hline & Total & 23 Orang
\end{tabular}

\section{Sumber: Data Primer diolah, 2021}

Paling banyak yang menjadi pedagang adalah laki-laki dengan jumlah 16 orang dibandingkan dengan pedagang perempuan yang hanya berjumlah 7 orang dan total pedagang yang menjual daging ekstrim di pasar ekstrim Wilken adalah 23 orang.

\section{Jenis Daging Yang Dijual}

Bebagai jenis daging yang dijual dan dibagi oleh beberapa pedagang dengan jenis daging yang berbeda-beda. Daging yang dijual di pasar ekstrim Tomohon terdiri dari Ular, Anjing, Babi Hutan, Tikus Hutan, Monyet, Biawak, Kodok, Kucing, dan Kelelawar. Dari Semua pedagang yang menjual daging ekstrim ada terbagai beberapa kelompok penjual yang menjual jenis daging berbeda-beda. Bisa dilihat pada table berikut ini. 
Tabel 3. Jenis Daging Yang Dijual Sesuai Kelompok Pedagang

\begin{tabular}{lll}
\hline No & Jenis Daging & Jumlah Pedagang \\
\hline 1 & Kelelawar & 3 Orang \\
2 & Ular & 5 Orang \\
3 & Tikus Hutan & 3 Orang \\
4 & Macam-macam daging & 12 Orang \\
\hline & Total & 23 Orang \\
\hline
\end{tabular}

Sumber: Data Primer diolah, 2021

Jumlah pedagang daging hanya menjual kelelwar berjumlah 3 orang, jumlah pedagang hanya menjual daging ular 5 orang dan jumlah pedagang yang menjual hanya daging tikus hutan 3 orang dan pedagang lainnya menjual lebih dari satu jenis daging atau bermacam-macam daging termasuk juga ular, tikus hutan, dan kelelawar.

\section{Manfaat Yang Mempengaruhi Pengembangan Keunikan dan Otentisitas Pasar Ekstrim Sebagai Daya Tarik Wisata}

Ada tiga manfaat yang mempengaruhi pengembangan pasar ekstrim khususnya terhadap keunikan dan otentisitas pasar tersebut, semua manfaat yang mempengaruhi pengembangan ini membuat keaslian dari hal unik yang ada menjadi sesuatu yang sangat otentik.

a. Budaya

Apa manfaat terhadap budaya dari keunikan dan otentisitas Pasar Ekstrim? sebagai daya tarik wisata di Kota Tomohon?

“Kemajuan pariwisata karena ada yang diberikan untuk wisatawan dalam bentuk pengetahuan lokal" (Randy Suoth, 29/7/2021). 
Keunikan dan Otentisitas Pasar Ekstrim Wilken Sebagai Daya Tarik Wisata di Kota Tomohon...

b. Lingkungan

Apa manfaat terhadap lingkungan dari keunikan dan otentisitas Pasar Ekstrim? sebagai daya tarik wisata di Kota Tomohon?

"Lingkungan yang sangat toleransi, karena penjual dan pembeli di pasar

Ekstrim Wilken Tomohon berasal dari berbagai daerah." (Gerry Rengku, $11 / 4 / 2021)$.

c. Ekonomi

Apa manfaat terhadap ekonomi dari keunikan dan otentisitas Pasar Ekstrim? sebagai daya tarik wisata di Kota Tomohon?

“Apa yang menjadi aktivitas dari setiap wisatawan memberikan dampak ekonomi bagi Kota Tomohon dari kegiatan wisata yang dilakukan". (Aditya Pondaag, 14/4/2021).

\section{Maknanya Menjadi Pedagang Pasar Ekstrim}

Fenomena yang dialami oleh setiap individu secara mendalam berbeda-beda, hal ini akan dibahas dengan para pedagang Pasar Ekstrim Wilken Tomohon yang berjumlah lima orang, terkait dengan keunikan dan otentisitas Pasar Ekstrim Wilken Tomohon sebagai daya tarik wisata di Kota Tomohon Sulawesi Utara. Dengan menggunakan metode wawancara mendalam dengan para pedagang pasar tentang apa yang di alami dan apa yang menjadi makna menjual daging ekstrim, makna keunikan dan otentisitas pasar ekstrim, Jenis-jenis daging yang dijual, dari mana sumber pasokan daging, berapa banyak permintaan daging, banyaknya daging yang laku per hari di pasar tradisional yang sekaligus menjadi tempat wisata. Secara fenomena apa yang di wawancarai, diobservasi, dan didokumentasi semuanya akan diuraikan secara terbuka 
a. Makna Menjual Daging Ekstrim

Apa makna menjual daging ekstrim di Pasar Ekstrim Wilken sebagai daya tarik wisata di Kota Tomohon?

"Keuntungan yang lebih besar daripada penjual daging yang biasa dikonsumsi." (Jhony Pangemanan, 14/4/2021).

b. Makna Keunikan dan Otentisitas Pasar Ekstrim

Apa makna keunikan dan otentisitas di Pasar Ekstrim Wilken sebagai daya tarik wisata di Kota Tomohon?

"Cuma ada di Sulawesi Utara para wisatawan boleh menemukan ada pasar ekstrim yang menjual macam-macam daging yang tidak biasa dimakan." (Flora Runtukahu, 14/4/2021).

c. Daging Hewan Apa Saja Yang Dijual

Daging hewan apa saja yang dijual di Pasar Ekstrim Wilken sebagai daya tarik wisata di Kota Tomohon?

"Selalu menyediakan daging ular meskipun sulit didapatkan tapi ini yang menjadi incaran para pembeli setiap kali datang ke tempat saya." (Flora Runtukahu, 14/4/2021).

"Saya menjual daging anjing, kucing, tikus hutan, dan babi hutan." (Albert Wuisan, 14/4/2021).

\section{d. Sumber Pasokan Daging Ekstrim}

Dari manakah sumber pasokan daging yang dijual di Pasar Ekstrim Wilken sebagai daya tarik wisata di Kota Tomohon?

"Saya biasanya mendapatkan daging untuk dijual ini dari daeral Sulawesi Tengah." (Jhony Pangemanan, 14/4/2021) 
Keunikan dan Otentisitas Pasar Ekstrim Wilken Sebagai Daya Tarik Wisata di Kota Tomohon...

e. Permintaan dan Penawaran Daging Ekstrim

Bagaimana permintaan dan penawaran daging ekstrim yang dijual di Pasar Wilken sabagai daya tarik wisata di Kota Tomohon?

"Permintaan daging setiap hari normal kecuali diakhir pekan permintaan daging yang saya jual itu pasti meningkat, itu karena hari sabtu adalah hari pasar yang paling lengkap di Pasar Ekstrim Wilken." (Jhony Pangemanan, $14 / 4 / 2021)$

f. Banyaknya Daging Yang Terjual Perhari Dapat dilihat pada tabel dibawah ini:

Tabel 4. Jumlah Daging Yang Terjual Perhari

\begin{tabular}{|c|c|c|c|c|}
\hline No & Jenis Daging & Harga & $\begin{array}{c}\text { Rata-rata Terjual } \\
\text { Perhari }\end{array}$ & Pendapatan \\
\hline 1 & Ular & $\mathrm{Rp} 60.000 / \mathrm{kg}$ & $37 \mathrm{~kg}$ & $\operatorname{Rp} 2.220 .000$ \\
\hline 2 & Kelelawar & Rp 100.000/5 ekor & 250 ekor & $\operatorname{Rp} 5.000 .000$ \\
\hline 3 & Tikus Hutan & Rp 100.000/3 ekor & 150 ekor & $\operatorname{Rp} 5.000 .000$ \\
\hline 4 & Anjing & Rp 1.000.000/ekor & 5 ekor & $\operatorname{Rp} 5.000 .000$ \\
\hline 5 & Babi Hutan & $\mathrm{Rp} 75.000 / \mathrm{kg}$ & $25 \mathrm{~kg}$ & $\operatorname{Rp} 1.875 .000$ \\
\hline 6 & Kucing & Rp 120.000/ekor & 4 ekor & $\operatorname{Rp} 480.000$ \\
\hline 7 & Biawak & Rp 140.000/ekor & 6 ekor & $\operatorname{Rp} 860.000$ \\
\hline 8 & Kodok & $\mathrm{Rp} 80.000 / \mathrm{kg}$ & $9 \mathrm{~kg}$ & $\operatorname{Rp} 720.000$ \\
\hline
\end{tabular}

Sumber: Data Primer diolah, 2021

Setiap pedagang memiliki pandangan berbeda-beda tentang keunikan dan otentisitas pasar ekstrim sebagai daya tarik wisata, namun sesuai dengan hasil wawancara dan observasi di Pasar Ekstrim Wilken Tomohon, keunikan yang ada berkaitan dengan daging-daging yang dijual dan kesempatan bagi mereka untuk berdagang, itu yang mebuat pasar ekstrim disebut juga otentik karena satu-satunya pasar yang ada di Indonesia dengan berbagai jenis daging hewan yang tidak lazim 
untuk dijual apalagi dikonsumsi. Tapi itulah yang menjelaskan dimana budaya orang Minahasa memang kental dan dengan adanya daging ini di Pasar Ekstrim Wilken Tomohon, mejadikan pasar ini unik dan otentik dengan nilainya sendiri melalui pedagang-pedagang pasar yang ada. Bisa dilihat pada gambar 1 ada proses jual beli dan tawar menawar antara penjual dan pembeli seperti biasanya yang terjadi di Pasar Ekstrim Tomohon.

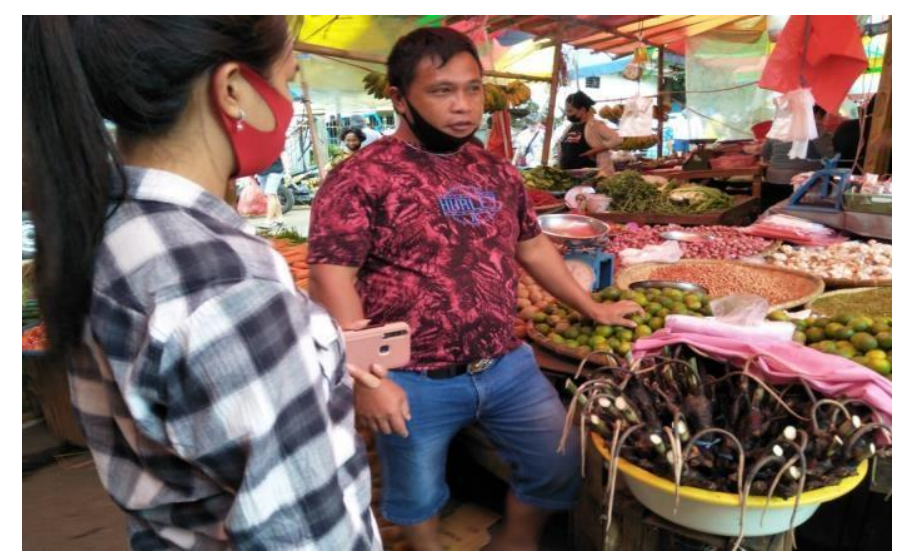

\section{Gambar 1. Pedagang Pasar Saat Menjual Daging Tikus Hutan}

Sumber: Dokumentasi Peneliti, 2021

Setiap pedagang ada cara menawarkan dagangan dengan teknik masingmasing, namun kabar baiknya bagi pedagang daging ekstrim tidak perlu lagi memasarkan lebih dagangan mereka karena sudah tersedia pasarnya sendiri dan permintaannya jelas, sebab tidak semua orang akan membeli daging ekstrim untuk dimasak, tapi setiap pedagang rata-rata sudah memiliki target pasarnya dengan sudah ada pelanggan tetap yang membeli setiap harinya, seperti para pemilik

usaha rumah makan Minahasa. 
Keunikan dan Otentisitas Pasar Ekstrim Wilken Sebagai Daya Tarik Wisata di Kota Tomohon...

\section{Maknanya Menjadi Pemangku Kepentingan (stakeholder) Pasar Ekstrim Wilken}

\section{Tomohon}

Metode fenomenologi yang digunakan untuk mengetahui makna sebagai pemangku kepentingan (stakeholder) Pasar Ekstrim Wilken Tomohon, hal ini akan dibahas dengan dinas pariwisata Kota Tomohon, Pengelolah Pasar, dan Biro Perjalanan yang berjumlah 7 orang, terkait dengan keunikan dan otentisitas Pasar Ekstrim Wilken Tomohon sebagai daya tarik wisata di Kota Tomohon Sulawesi Utara. Dengan menggunakan metode wawancara mendalam dengan dua orang staf dinas pariwisata, tiga orang pengelolah pasar, dan 2 orang pemandu wisata tentang apa yang di alami dan apa yang menjadi tanggung jawab sebagai pemangku kepentingan di pasar ekstrim, makna keunikan dan otentisitas pasar ekstrim, strategi pengembangan pasar sebagai daya tarik wisata yang berkelanjutan, harapan sebagai pemangku kepentingan untuk pasar ekstrim sebagai daya tarik wisata berkelanjutan yang ada di Kota Tomohon. Secara fenomena apa yang di wawancarai, diobservasi, dan didokumentasi semuanya akan diuraikan secara terbuka dan jelas.

a. Tanggung Jawab Sebagai Pemangku Kepentingan (stakeholder) Pasar Ekstrim Apa yang menjadi tanggung jawab sebagai pemangku kepentingan dibidang pariwisata untuk pengembangan keunikan dan otentisitas Pasar Ekstrim sebagai daya tarik wisata di Kota Tomohon?

"Menjaga keadaan pasar ekstrim karena merupakan kearifan lokal, bertanggung jawab untuk terus menjaga kebersihan pasar, melihat perkembangan" (Pingkan, 21/5/2021)

b. Makna Keunikan dan Otentisitas Pasar

Apa makna keunikan dan otentisitas Pasar Ekstrim sebagai daya tarik wisata di Kota Tomohon? 
“Bertahannya budaya orang Minahasa memakan daging ekstrim seperti ular, anjing, babi huta, tikus hutan dan lain-lain." (Amalia, 21/5/2021)

c. Strategi Pengembangan Pasar Sebagai Daya Tarik Wisata Berkelanjutan

Apa strategi pemerintah khususnya dinas pariwisata untuk pengembangan Pasar Ekstrim sebagai daya tarik wisata di Kota Tomohon?

“Membuat sebuah paket destinasi yang lengkap dari pasar ekstrim hingga bisa mencici makanan ekstrim" (Randy Suoth, 29/7/2021)

d. Harapan Pemangku Kepentingan (stakeholder) Pasar Ekstrim Sebagai Daya Tarik Wisata

Apa harapan pemerintah khususnya dinas pariwisata untuk pengembangan Pasar Ekstrim sebagai daya tarik wisata di Kota Tomohon?

"Masyarakat dan pedagang ada rasa memiliki budaya lokal dan mempertahankan hak sebagai pedagang dan pembeli yang tidak merasa terganggu meskipun banyak masukan dan kritik tentang apa yang dijual bahkan apa yang dimakan." (Christian Wowiling, 14/4/2021)

\section{Simpulan dan Saran}

\section{Simpulan}

Berdasarkan hasil dari penelitian tentang Keunikan dan Otentisistas Pasar Ekstrim Wilken Tomohon diperoleh simpulan sebagai berikut.

1. Manfaat yang mempengaruhi keunikan dan otentisitas pasar

Ada tiga manfaat yang mempengaruhi keunikan dan Otentisitas pasar Ekstrim Wilken Tomohon yang berdasarkan tanggapan informan dan hasil dari penelitian yang dilakukan yaitu: 
Keunikan dan Otentisitas Pasar Ekstrim Wilken Sebagai Daya Tarik Wisata di Kota Tomohon...

a) Budaya

Dilihat dengan adanya keunikan dan otentisitas pasar ekstrim budaya masyarakat seperti penjual daging ekstrim dapat melibatkan diri untuk sesuatu yang menarik perhatian yaitu menjual daging ular dan babi hutan seperti sekarang demi melestarikan kearifan lokal adat suku Minahasa. Karena dengan menjual daging yang disebut ekstrim seperti ini para pedagang masih tetap bisa membiasakan diri untuk menarik minat wisatawan agar tetap datang berkunjung di pasar ekstrim walaupun hanya melihat saja namun pasti ada sesuatu yang berhubungan dengan budaya lokal orang minahasa yang akan wisatawan ingat pastinya sesuatu yang unik.

Budaya penggunaan bahasa daerah juga semakin terlihat saat proses jual beli ada juga proses tawar menawar yang dilakukan oleh pembeli yang berasal dari masyarakat lokal dan masih tetap menggunakan bahasa daerah Minahasa yaitu bahasa Tombulu yang sekarang jarang digunakan sehari-hari.

b) Lingkungan

Saat berbelanja di pasar ekstrim Wilken Tomohon wisatawan akan mendapatkan pengalaman berbelanja yang mungkin berbeda dari pasar lainnya, dimana wisatawan akan menemukan lingkungan yang sangat toleransi, karena penjual dan pembeli di pasar Ekstrim Wilken Tomohon adalah berasal dari berbagai daerah, Bahkan ada yang dari luar provinsi seperti dari Gorontalo.

Lingkungan yang bersih, aman, dan meiliki keunikan sebagai suatu destinasi adalah suatu kekuatan yang unggul untuk dijadikan daya tarik wisata apalagi di pasar tradisional yang pada umumnya bukan tempat yang rapih, harum, dan bersih layaknya tempat wisata lainnya. Namun di Pasar Ekstrim Wilken Tomohon bisa melihat perbedaan yaitu pasar yang ditata sebagai pasar yang layak dikunjungi sebagai tempat wisata karena sebagian fasilitas yang telah dipenuhi seperti toilet, akses jalan, transportasi dan atraksi lainnya. 
c) Ekonomi

Pasar ekstrim Wilken Tomohon adalah pasar tradisional terbesar di Sulawesi Utara, dimana ini menjadi sangat penting untuk peningkatan ekonomi masyarakat Tomohon. Karena adanya pasar ini masyarakat lokal dapat berdagang daging buruan mereka dan dengan mudah memasarkan hasil dari perkebunan mereka, bukan hanya bahan makanan tapi juga berbagai macam bunga dijual disana, membuat masyarakat lebih giat untuk meningkatkan hasil perkebunan dan penangkapan hewan mereka, karena ada tempat yang menjanjikan untuk meraka berdagang yaitu pasar ekstrim Wilken Tomohon.

Adanya pasar ini masyarakat bisa mendapatkan penghasilan setiap hari karena bisa berdagang untuk memenuhi permintaan pembeli dan karena proses transaksi yang unik juga bisa dilihat di pasar ini yang sering menggunakan bahasa daerah orang Minahasa Induk yaitu bahasa Tombulu yang merupakan sesuatu yang unik bagi wisatawan.

\section{Makna Menjadi Seorang Pedagang Pasar Ekstrim}

Makna yang dirasakan oleh para pedagang yaitu keterlibatan langsung dengan wisatawan berkaitan dengan keunikan dan otentisitas pasar sehingga membuat mereka beriteraksi langsung sambil menjelaskan jika ada wisatawan yang datang hanya sekeder bertanya.

Daging yang paling banyak diminati oleh masyarakat Minahasa atau pembeli yang datang adalah daging ular, anjing, dan kelelelawar. Dilihat dari permintaan yang ada dan penawaran dari sumber pemasok daging, dan ada begitu banyak restoran Minahasa yang datang sebagai pembeli tetap atau berlangganan dengan pedagang-pedagang pasar.

Makna keunikan dan otentisitas sebagai pedagang adalah diajukan beberapa pertanyaan dari berbagai wartawan yang sering datang dan juga oleh wisatawan 
karena merupakan sesuatu yang unik menjual daging ekstrim, dan otentik sekali apa yang dijual bisa dijadikan sumber penghasilan tambahan oleh pemerintah daerah Kota Tomohon sebab sebagai penjual juga bisa merasa dibutuhkan bukan hanya oleh orang Minahasa yang membeli daging tapi juga sebagai sumber informasi dalam memasarkan budaya kearifan lokal orang Minahasa kepada mereka yang tidak paham tentang budaya Minahasa soal makan daging ekstrim.

\section{Makna Menjadi Pemangku Kepentingan di Pasar Ekstrim}

Pengelolah pasar dan pemerintah khususnya Dinas Pariwisata bisa memasarkan potensi pasar untuk meningkatkan tingkat ekonomi Kota Tomohon melalui kontribusi yang berjalan dengan terus mempertahankan pasar sebagai daya tarik wisata karena otetisitas pasar ini bisa terus ada dan membantu pengembangan pariwisata di Sulawesi Utara melalui wisata budaya dan wisata kuliner yang ada.

\section{Saran}

Adapun saran dalam penelitian ini tentang keunikan dan otentisitas Pasar Ekstrim Wilken Tomohon sebagai daya tarik wisata adalah:

1) Bagi Pedagang Pasar

Harus lebih aktif jika ada wisatawan yang datang di pasar untuk menyaksikan apa yang dijual meskipun mereka tidak membeli daging tersebut tapi wisatawan yang datang pasti akan mengalami pengalaman yang unik dan menarik dan tidak ditemukan di tempat lain. Pedagang diharapkan agar terus menjaga ketersediaan pasokan daging ekstrim supaya pasar ini terus ada dan menjadi daya tarik bagi wisatawan secara berkelanjutan.

\section{2) Bagi Pengelolah Pasar dan Pemerintah Kota Tomohon}

Seharusnya dapat memberikan fasilitas seperti tempat pusat informasi bagi wisatawan di lingkungan pasar agar siapapun wisatawan yang datang bisa 
mendapatkan informasi dengan benar jika takut untuk melihat langsung jenis-jenis daging yang dijual dan suasana pasar yang banyak darah binatang.

Belum memiliki akses untuk menerima secara tertulis komentar wisatawan, atau belum mampu menjaring komentar wisatawan tentang saran atau kritik untuk pasar ekstrim.

3) Bagi peneliti selanjutnya

Saran bagi peneliti selanjutnya, supaya peneliti lebih dalam lagi untuk menggali informasi yang belum tercangkup berkaitan dengan keunikan dan otentisitas sebagai daya tarik wisata dengan menjaga kebudayaan, kelestarian lingkungan dan ekonomi yang ada.

\section{Ucapan Terima Kasih}

Penulis mengucapkan terima kasih kepada pembimbing Prof. Dr. Ir. I Gde Pitana, M..Sc, dan pembimbing II, Gde Indra Bhaskara, SST.Par, M.Par, Ph.D. atas waktu untuk bimbingan, koreksi, masukan dan saran dalam penyelesaian tesis ini. Ucapan terima kasih juga penulis sampaikan kepada dosen penguji yaitu Prof. Dr. I Nyoman Darma Putra, M.Litt. Dr. Drs. I Nyoman Sunarta, M.Si, Ni Made Sofia Wijaya, SST.Par., M.Par., Ph.D. dan tentu juga pedagang pasar ekstrim, pembeli, stakeholders Pengelolah Pasar, Dinas Pariwisata Kota Tomohon, Biro Perjalanan dan jajarannya atas waktu untuk berdiskusi singkat dengan menyampaikan pendapat terkait Keunikan Dan Otentisitas Pasar Ekstrim Wilken Sebagai Daya Tarik Wisata Di Kota Tomohon Sulawesi Utara.

\section{Daftar Pustaka}

A Chariri dan Imam Ghozali. 2007. “Teori Akuntansi”. Semarang: Badan Penerbit Universitas Diponegoro. 
A. Smith, J. 2009. Psikologi Kualitatif. Yogyakarta: Pustaka Pelajar, 52.

Adam Kuper \& Jesica Kuper. 2000. Ensiklopedi Ilmu-Ilmu Sosial. Jakarta: Rajawali Press.

Ales Gacnik. 2012. Gastronomy Heritage as a Source of Development for Gastronomy Tourism and as a Means of Increasing Slovenia's Tourism Visibility

Ardika, I Wayan. 2011. "Gastronomi dalam Pariwisata Budaya”, dalam I Nyoman Darma Putra dan I Gde Pitana (eds) Pemberdayaan \& Hiperdemokrasi dalam Pembangunan Pariwisata, Persembahan untuk prof. Ida Bagus Adnyana Manuaba, pp.17-27. Denpasar: Pustaka Larasan.

Budimanta., et al. 2008. Corporate Social Responsibility alternatif bagi pembangunan Indonesia. Cetakan kedua. Jakarta: ICSD

Dafila Tanico, 2016. “Melestarikan Minuman Tradisional Khas Jawa Timur Sebagai Potensi Pengembangan Wisata Kuliner (Culinary Tourism)"

Daniel Joseph Boorstin, 1964. "The Image: A Guide to Pseudo-events in America" Dean MacCannell, 1989. "Semiotics of Tourism"

Denzin andY. Lincoln. (1994), Handbook of Qualitative Research. London: Sage.

Derek R. Hall, Irene Kirkpatrick, Morag Mitchell 2005. Rural Tourism and Sustainable Business.

Didin Syarifuddin, Chairil M Noor, Acep Rohendi, 2018. “Memaknai Kuliner Lokal Sebagai Daya Tarik Wisata Kota Bandung"

Dwi Wulandari, 2015, “Kemenpar Rilis Lima Destinasi Wisata Kuliner Unggulan” November, hal.17

Fadiati, Ari. 2011. Mengelola Usaha Jasa Boga Yang Sukses. Bandung: PT. Remaja Rosdakarya.

Fakeye, P. C., \& Crompton, J. L. 1991. Image differences between prospective, first-time, and repeat visitors to the Lower Rio Grande Valley. Journal of.

Fletcher RJ, et al. 2003. The structure and function of MCM from archaeal $M$. Thermoautotrophicum.

Gilarso, T. SJ. 2003. "Pengantar Ilmu Ekonomi Mikro”. Yogyakarta: Kanisius.

Greg Richards. 2002. Gastronomy: an essential ingredient in tourism production and consumption?

Hanurawan, Fattah. 2012. Psikologi Sosial. Bandung: PT Remaja Rosdakarya Offset.

Harvey, Ena. 2012. Management Coordinator-Caribbean \& Agrotourism Specialist. 13 th Annual Caribbean Confrence on Sustainable Tourism Development

Hu, Y. and Ritchie, J. 1993. "Measuring destination attractiveness: a contextual approach", Journal of Travel Research, Vol. 32, pp. 25-34 
Hunt, J.D. 1975 Image as a Faktor in Tourism Development. Journal of Travel Research, 13, 1-7.

Islam Hassouneh, Amr Radwan, Teresa Serra and Jose M. Gil. 2012. "Food Scare Crises and Developing Countries: The Impact of Avian Influenza on Vertical Price Transmission in The Egyptian Poultry Sector"

Janet Hanlan, Stephen Kelly 2002. Image formation, information sources and an iconic Australian tourist destination.

Jerry Hopkins. 2006. "Extreme Cuisine The Weird E Wonderful Foods That People Eat"

Kadariah, 1994. "Teori Ekonomi Mikroi", Lembaga Penerbit FE-UI, Jakarta. Kuncoro, Mudrajad. 2003. Metode Riset untuk Bisnis \& Ekonomi. Jakarta: Erlangga.

Mankiw, 2000, Makroekonomi Edisi ke Enam, Erlangga, Jakarta

Mario Barreto dan Ketut Giantari, 2015."Strategi Pengembangan Objek Wisata Air Panas Di Desa Marobo, Kabupaten Bobonaro Timor Leste", E-Jurnal Ekonomi dan Bisnis Universitas Udayana Bali, Vol.4:11.2015.

McKerchera dan Prideauxb, 2011. Are tourism impacts low on personal environmental agendas?

Michel Picard. 2006. Pariwisata Budaya dan Budaya Pariwisata

Mimin Haryati, 2007. Model dan Teknik Penilaian pada Tingkat Satuan Pendidikan.Gaung Persada Press. Jakarta.

Nasution. 1996. Metode Penelitian Kualitatif Naturalistik. Jakarta : Sinar Grafika.

Ni Nyoman Widani dan A.A Ketut Sri Candrawati. 2019. “Be Jangkrik dan Be Bluang Sebagai Kuliner Musiman di Bali"

Nummedal, M. and Hall, C.M. 2006. Local Food in Tourism: An Investigation of the New Zealand South Island's Bed and Breakfast Sector's Use and Perception of Local Food. Tourism Review International, 9, 365-378.

Pitana, I. Gde dan Gayatri, PutuG. 2005. Sosiologi Pariwisata. Yokyakarta:Andi. Rankin, M. et al. 2012. Contemporary Issues in Accounting. Australia, Queensland: Jhon Wiley \& Sons Australia Ltd.

Reed et al. 2009. Who's in and why? A typology of stakeholder analysis methods for natural resource management

Rosyidi, Suherman. 2005. Pengantar Teori-Teori Ekonomi: Pendekatan Kepada Teori Makro dan Mikro. Jakarta: PT. Rajawali Grafindo Persada

Sadono, Sukirno. 2010. Makroekonomi. Teori Pengantar. Edisi Ketiga. PT. Raja Grasindo Perseda. Jakarta.

Scott, D. G. 2006. Socialising the stranger: Hospitality as a relational reality (Dissertation). Retrieved from http://hdl.handle.net/10523/1283 
Sönmez, S. and E. Sirakaya 2002. A Distorted Destination Image? The Case of Turkey. Journal of Travel Research, 41(2):185-196.

Soteriades, M. 2012, "Tourism destination marketing: approaches improving effectiveness and efficiency", Journal of Hospitality and Tourism Technology, Vol. 3 No. 2, pp. 107-120.

Sugiyono. 2010. Metode Penelitian Pendidikan Pendekatan Kuantitatif, kualitatif, dan R\&D. Bandung: Alfabeta

Sukirno, Sadono. 2006. Makroekonomi: Teori Pengantar (edisi ke tiga). Jakarta: Rajawali Press.

Sukmadinata. 2010. Metode penenelitian pendidikan. Bandung: PT Remaja Rosdakarya.

Stone, 2005 P.R. Stone Dark tourism consumption - a call for research e-Review of Tourism Research, 3 (5) (2005), pp. 109-117

Vincent Nijman. 2015. "Water Monitor Lizards for Sale as Novelty Food in Java, Indonesia", Oxford Brookes University OX0 1BP, Oxford, UK

Warpani. 2007. Pariwisata Dalam Tata Ruang Wilayah. Development of regional tourism planning in Indonesia.

Yoeti, 1997.Perencanaan dan Pengembangan PARIWISATA

Zadrak M Warouw, V V.J Panelewen, Arie D.P Mirah .2014. Analisis Usaha Peternakan Babi Pada Perusahan "Kasewean” Kakaskasen II Kota Tomohon.

Sumber Online:

https://nusadaily.com/travel/pasar-beriman-tomohon-pasar-Ekstrim-yangmendunia.html. Pasar Tomohon. https://nusadaily.com/travel/pasarberiman- tomohon-pasar-Ekstrim-yang-mendunia.html (Diakses pada tanggal 8 Januari 2021 9.32.pm)

https://irto.id/kisah-pasar-Ekstrim-tomohon-secuplik-perlawanan-dan-leluconevDs.

Kisah Pasar Ekstrim Tomohon Petrik Matanasi. Februari 2020. https://irto.id/kisahpasar-Ekstrim-tomohon-secuplik-perlawanan-dan-lelucon-evDs (Diakses pada tanggal 7 Januari 2021 8.55.pm)

https://www.dictio.id/t/bagaimana-metode-penelitian-dengan-menggunakanpendekatan-fenomenologi/117068/2 (Diakses pada tanggal 13 april 2021 8.13.pm) 


\section{Profil Penulis}

Ingryt Grity Adipati menyelesaikan studi diploma IV Program Studi Manajemen Perhotelan di Politeknik Negeri Manado pada tahun 2016, dan pada tahun 2019 melanjutkan Pendidikan Program Magister di Program Studi Kajian Pariwisata, Universitas Udayana Bali.

I Gde Pitana adalah Guru Besar Pariwisata Universitas Udayana dan beliau menjabat sebagai dosen tetap pada Prodi Agribisnis Fakultas Pertanian Universitas Udayana. Beliau meraih gelar sarjana di Fakultas Pertanian Universitas Udayana pada tahun 1984, gelar S2 pada jurusan Sociology-Antropology di Ateneo De Manila Uni Philipina pada tahun 1989 dan gelar S3 dengan jurusan yang sama di The Australian National University pada tahun 1997. Beliau pernah menjabat sebagai Kepala Dinas Pariwisata Provinsi Bali (2001-2004), Kepala Puslitbangpar Kemenbudpar (2005-2008), Direktur Promosi Pariwisata Luar Negeri, Kemenbudpar RI (2008- 2010), Kepala Badan Pengembangan Sumberdaya Budpar, Kemenbudpar RI (2010- 2012), Kepala Badan Pengembangan Sumberdaya Parekraf, Kemenparekraf RI (2012-1014), Plt. Dirjen Ekonomi Kreatif Berbasis Iptek dan Desain Kemenparekraf RI (2012), Plt. Dirjen Sejarah dan Purbakala (Dirjen Kebudayaan), Kementerian Budpar/Kemendikbud (2011-2012), Deputi Menteri bidang Pengembangan Pemasaran Mancanegara, Kemenpar RI (2015-2018), Deputi Menteri bidang Pengembangan Pemasaran I, Kemenpar RI (2018-2018, 5 Jan-1 Agustus), dan Tenaga Ahli Menteri Pariwisata, bdg Pemasaran dan Kerjasama Pariwisata (2018-2019).

Gde Indra Bhaskara adalah dosen tetap Universitas Udayana. Beliau alumnus Sarjana Sains Terapan di Sekolah Tinggi Pariwisata Nusa Dua Bali pada tahun 2001 dan melanjutkan program Master ke Bournemouth University pada tahun 2002-2001. Kembali dari Inggris, beliau bekerja pada HES Global, sebuah perusahaan terkemuka yang memfokuskan dalam mencari dan menempakan eksekutif/pemimpinpemimpin perusahaan di seluruh dunia pada industri perhotelan dan jasa, pada 
kurun waktu 2004- 2006. Pada periode berikutnya, beliau mengajar di Manajemen Perhotelan Indonesia yang dikenal dengan nama MAPINDO. Menghabiskan waktu dua tahu disana, pada tahun 2008 beliau diterima di Universitas Udayana sebagai dosen tetap. Hanya berkesempatan mengajar dua semester setelah diangkat menjadi dosen tetap di Universitas Udayana, beliau mendapatkan beasiswa untuk melanjutkan pendidikan S3 ke Bournemouth University di tahun 2010. 